\title{
Hypothyroidism Treatment Among Older Adults: Evidence from a Claims Database
}

\author{
Maureen J. Lage $\cdot$ Ramon Espaillat · Jamie Vora $\cdot$ Zsolt Hepp
}

Received: February 6, 2020 / Published online: April 11, 2020

(C) The Author(s) 2020

\begin{abstract}
Introduction: Hypothyroidism is a common but often unrecognized condition associated with significant morbidity in the older adult population. This study characterizes a large population of older adults diagnosed with hypothyroidism and examines concordance of their treatment with recommendations from expert bodies, e.g., the American Thyroid Association and American Association of Clinical Endocrinologists.

Methods: Individuals seen in general and/or specialty practices who were age $\geq 65$ years and diagnosed with hypothyroidism were included in this observational, retrospective cohort study using a large US claims database. Analyses describe the population and examine the
\end{abstract}

Digital Features To view digital features for this article go to https://doi.org/10.6084/m9.figshare.11961417.

M. J. Lage

HealthMetrics Outcomes Research LLC, 27576 River

Reach Drive, Bonita Springs, FL 34134, USA

R. Espaillat $(\bowtie) \cdot J$. Vora $\cdot$ Z. Hepp

AbbVie, Inc., 26525 North Riverwoods Boulevard,

North Chicago, IL 60045, USA

e-mail: ramon.espaillat@abbvie.com prevalence of hypothyroidism, treatment with levothyroxine and, among those treated, whether TSH laboratory values are within a guideline-recommended target range.

Results: Prevalence of hypothyroidism in this older adult population increased from $5.62 \%$ to $8.24 \%$ over the $2007-2015$ period. Among older adults diagnosed with hypothyroidism $(N=4025)$, a substantial proportion $(28.0 \%)$ did not receive levothyroxine therapy, and, of those who were receiving such therapy $(N=2899)$, $32.9 \%$ did not have evidence of being monitored to determine whether the dosage was appropriate. Moreover, the laboratory results of those who were treated suggest that a significant proportion (17.4\%) had a TSH level above the recommended target range, while TSH levels for a smaller proportion (3.7\%) were below target.

Conclusions: Many older adults diagnosed with hypothyroidism may not have received medical care complying with clinical practice guidelines. Results of this study reveal a number of areas to target to potentially improve the treatment of older adults with hypothyroidism.

Keywords: Hypothyroidism; Levothyroxine; Older adults; Treatment 


\section{Key Summary Points}

Why carry out this study?

Hypothyroidism (overt and subclinical) is common in the USA, rates tend to increase with age, and it is associated with adverse clinical outcomes

Clinical guidelines recommend screening for hypothyroidism among older adults and, if treatment with levothyroxine is indicated, monitoring of thyroidstimulating hormone (TSH) levels

This study describes treatment of older adults diagnosed with hypothyroidism and examines the concurrence between clinical practice recommended target levels of TSH and the levels actually achieved in clinical practice

\section{What was learned from the study?}

Among the older adults with hypothyroidism in an insured US population, $72.0 \%$ were treated with levothyroxine

Among the treated, $32.9 \%$ did not have their TSH level monitored in the first year following treatment and less than half, $46.4 \%$, attained the target range

Results of this study reveal a number of areas to target to potentially improve the treatment of older adults with hypothyroidism

\section{INTRODUCTION}

Hypothyroidism is a common disease that currently affects $4.6 \%$ of the US population [overt hypothyroidism is $0.3 \%$ and subclinical hypothyroidism (SCH) is 4.3\%] [1], and $>12 \%$ of Americans will develop a thyroid condition at some point during their lifetimes [2]. Most hypothyroidism in the US is caused by
Hashimoto's thyroiditis [3, 4], which is one of the most prevalent autoimmune conditions in the nation [5]. For instance, 791.7 out of every 100,000 individuals in the US have Hashimoto's thyroiditis, whereas 480.0 per 100,000 people have type 1 diabetes and 58.3 per 100,000 have multiple sclerosis [6]. Moreover, the prevalence of SCH increases with age, particularly among females and Caucasians $[1,7,8]$. One study of hypothyroidism among US adults aged $\geq 65$ years found that the rate of SCH was $15.0 \%$, while the frequency of overt hypothyroidism was $1.6 \%$ [9]. Other research has reported that $3-15 \%$ of individuals aged $\geq 60$ years have $\mathrm{SCH}$ [10].

Despite its prevalence, hypothyroidism is difficult to diagnose among older individuals since many symptoms are nonspecific and may be attributed to other common conditions, including depression and anemia [11]. Furthermore, diagnosis is made more challenging in this population since slightly elevated serum thyroid-stimulating hormone (TSH) levels may be a normal characteristic of the aging process rather than a reflection of disease [12-14] Perhaps due to these complexities, an estimated $1.3 \%$ of men and $1.0 \%$ of women $>60$ years old have unrecognized cases of overt hypothyroidism [15]. Both overt hypothyroidism and SCH in older patients are associated with higher cardiovascular risk $[16,17]$, an increased risk of hip fractures among men [18] and mortality $[17,19]$.

The American Thyroid Association (ATA) and American Association of Clinical Endocrinologists (AACE) published guidelines that recommend "screening for hypothyroidism should be considered in patients over the age of 60 ," and screening for hypothyroidism is also recommended for patients diagnosed with diseases that are common among older Americans, e.g., cardiac dysrhythmia, congestive heart failure and hypertension [14]. Guidelines further advise that patients $>50-60$ years old with hypothyroidism should be treated with levothyroxine, although the dose is dependent upon evidence of comorbid coronary artery disease [14]. However, treatment of older adults with $\mathrm{SCH}$ has been and continues to be controversial. A number of studies have shown lack 
of benefit of levothyroxine treatment in patients $>65$ years old $[9-11,16,20,21]$. Nevertheless, consideration of treatment of SCH may be warranted as the risk of developing overt hypothyroidism has been shown to increase as TSH levels rise, particularly in the presence of anti-thyroid peroxidase antibodies [14, 22-24].

Given the importance of the above issues, the aging of the US population, and increasing number of people aged $\geq 65$ years, the goal of this study was to characterize a population of older adults with hypothyroidism in terms of demographics, comorbidities and treatments received in clinical practice. In addition, this study compared the characteristics of patients who were treated with levothyroxine to those who were untreated. Finally, for those treated with levothyroxine, this investigation examined the concordance between the TSH levels that patients achieved and recommended target levels.

\section{METHODS}

Data for this retrospective, descriptive study came from the Optum Clinformatics ${ }^{\mathrm{TM}}$ database, which contains information from insurance claims for $>150$ million insured individuals. The database has information on patient demographics, inpatient and outpatient services, as well as outpatient prescription drugs. Optum Clinformatics ${ }^{\mathrm{TM}}$ also has laboratory test results for $>30$ million lives. Information contained in the Optum Clinformatics ${ }^{\mathrm{TM}}$ database was verified, adjudicated and adjusted before release and is fully deidentified and Health Insurance Portability and Accountability Act (HIPAA) compliant. The databases have been employed in $>90$ published research studies. Given the retrospective nature of the study design and the de-identified data, the study was exempt from internal review board evaluation.

Prevalence of diagnosed hypothyroidism was examined over the years 2007-2015 among insured, older adults. Cases were defined as individuals who, in the year of interest, were aged $\geq 65$ years and identified with hypothyroidism based upon either (1) inclusion of two or more ICD-9-CM codes for hypothyroidism (ICD-9-CM codes 243.xx-244.xx, except $244.2 x$ and $244.3 \mathrm{c}$ ) as found in the claims record, or (2) receipt of one such ICD-9-CM code for hypothyroidism and the individual had filled at least one prescription for levothyroxine. The individual was also required to have had continuous insurance coverage over the calendar year examined. The denominator for the prevalence estimates included all individuals aged $\geq 65$ years who had continuous insurance coverage over the relevant year.

For analyses of treatments and outcomes, data from the years 2014-2015 were used. Patients were identified with hypothyroidism during the calendar year 2014 based upon either (1) inclusion of two or more ICD-9-CM codes for hypothyroidism (ICD-9-CM codes of 243.xx244.xx, except $244.2 \mathrm{x}$ and $244.3 \mathrm{c}$ ) as found in the claims record, or (2) receipt of one such ICD-9-CM code for hypothyroidism and the individual had filled at least one prescription for levothyroxine. The index date was defined as the first date in 2014 the individual met any of the hypothyroidism criteria. Patients were also required to have been aged $\geq 65$ years as of the index date and to have been insured continuously from the index date through 1 year following the index date, i.e., the study period. Individuals were excluded if they received a diagnosis of thyroid cancer at any time during the study period. Because laboratories are not required to share test results (particularly, for this study, TSH test results) as part of an insurance claim, individuals were required to have in their record at least one laboratory test for any cause over the study period as evidence that the patient did have tests performed at laboratories that shared tests with the database vendor. Treated hypothyroid individuals were identified by having filled at least one prescription for levothyroxine over the study period while those who did not fill any prescriptions for levothyroxine were classified as untreated.

The main analyses describe patient characteristics and treatment outcomes for the treated and untreated cohorts. Specifically, patient characteristics included age, region of residence, type of insurance coverage, whether the diagnosing physician was an endocrinologist and 
general health, as assessed by the Charlson Comorbidity Index (CCI) score [25, 26]. Comorbidities were selected for this analysis based on associations with hypothyroidism found in either previous research [27-29] or the clinical practice guidelines issued by AACE/ATA [14]. Specifically, the comorbidities considered included bipolar disorder, coronary artery disease, depression, heart failure, hypertension, migraine, obesity, rheumatoid arthritis, type 1 diabetes and type 2 diabetes. Note that Addison's disease, celiac disease, chronic kidney disease, myasthenia gravis, pernicious anemia, schizophrenia and systemic lupus erythematosus were also considered. However, due to the infrequency of these conditions in this population $(<2 \%)$, these results are not reported.

The linked laboratory data was employed to examine whether patients treated with levothyroxine had their TSH monitored and, if so, whether TSH levels were within the targeted range identified by AACE/ATA. The last TSH test value, if any, recorded in the data during the study period was used for this purpose. In the main analysis, the target range for THS was $0.45-4.12 \mathrm{mIU} / \mathrm{l}$, as recommended by the AACE/ATA guidelines [14]. For this study, patients whose TSH levels were within the recommended target range were identified as on target. Individuals whose TSH levels were above or below the recommended range were identified as above or under target, respectively. Sensitivity analyses examined the robustness of these results by applying a broader TSH range of $0.45-4.5 \mathrm{mIU} / \mathrm{l}$ as recommended in updated treatment guidelines [30] and that has been classified as euthyroid for older adults [9]. Sensitivity analyses also examined the impact of requiring at least two TSH tests over the year, as is recommended for patients who initiate therapy on levothyroxine [14].

Means and standard deviations (SD) or medians and interquartile ranges (IQ) are presented for continuous variables, while frequencies and percentages are presented for categorical variables. ANOVAs, Wilcoxon signed-rank sum tests, $t$ tests and chi-square statistics were used to examine differences between groups. All analyses were conducted using SAS, version 9.4 (Cary, NC), and a
$P$ value $<0.05$ was considered, a priori, to be statistically significant.

\section{RESULTS}

In this older adult, insured, US population, the prevalence of hypothyroidism increased from $5.62 \%$ in 2007 to $8.24 \%$ in 2015 (Fig. 1). As expected $[1,7,31]$, the prevalence of hypothyroidism was higher for older women than older men (e.g., $12.66 \%$ vs. $4.48 \%$ in 2015 ).

There were 4025 older adults who met the study's criteria and were included in the analyses of treatment and TSH laboratory outcomes. Figure 2 illustrates how each of the inclusion and exclusion criteria affected the sample size. Table 1 characterizes at baseline the older adults with hypothyroidism in this study, showing that, overall, the average age was 69.4 years, and the majority were female $(68.5 \%)$, were insured via point of service (POS) insurance plans $(68.2 \%)$ and resided in the South (51.6\%). The comorbidities with the highest prevalence were dyslipidemia (75.6\%), hypertension (69.3\%), type 2 diabetes $(28.7 \%)$, coronary artery disease $(17.0 \%)$, obesity (17.0\%) and depression $(12.8 \%)$. In general, these patients were in poor general health, as evidenced by a high mean CCI score $(1.5 \pm 2.0)$ and high rates of the comorbidities examined. Almost three-quarters (72.0\%) of these older adults diagnosed with hypothyroidism were treated with levothyroxine.

Table 1 also compares patients treated with levothyroxine with those untreated, showing that treated patients, compared with untreated patients, were statistically significantly older (69.5 years vs. 69.0 years; $P=0.003$ ), more likely to be male $(32.6 \%$ vs. $28.6 \% ; P=0.013)$ and less likely to be diagnosed with hypothyroidism by an endocrinologist $(4.1 \%$ vs. $8.2 \%$; $P<0.001)$. Older patients treated with levothyroxine also appeared to be in poorer general health than untreated patients, as illustrated by the significantly higher CCI score (1.6 vs. $1.3 ; P<0.001)$ and higher rates of comorbid type 2 diabetes $(29.6 \%$ vs. $26.1 \%$; $P=0.027)$, hypertension $(70.5 \%$ vs, $66.2 \%$; $P=0.007)$, heart failure $(6.7 \%$ vs. $4.5 \%$; 


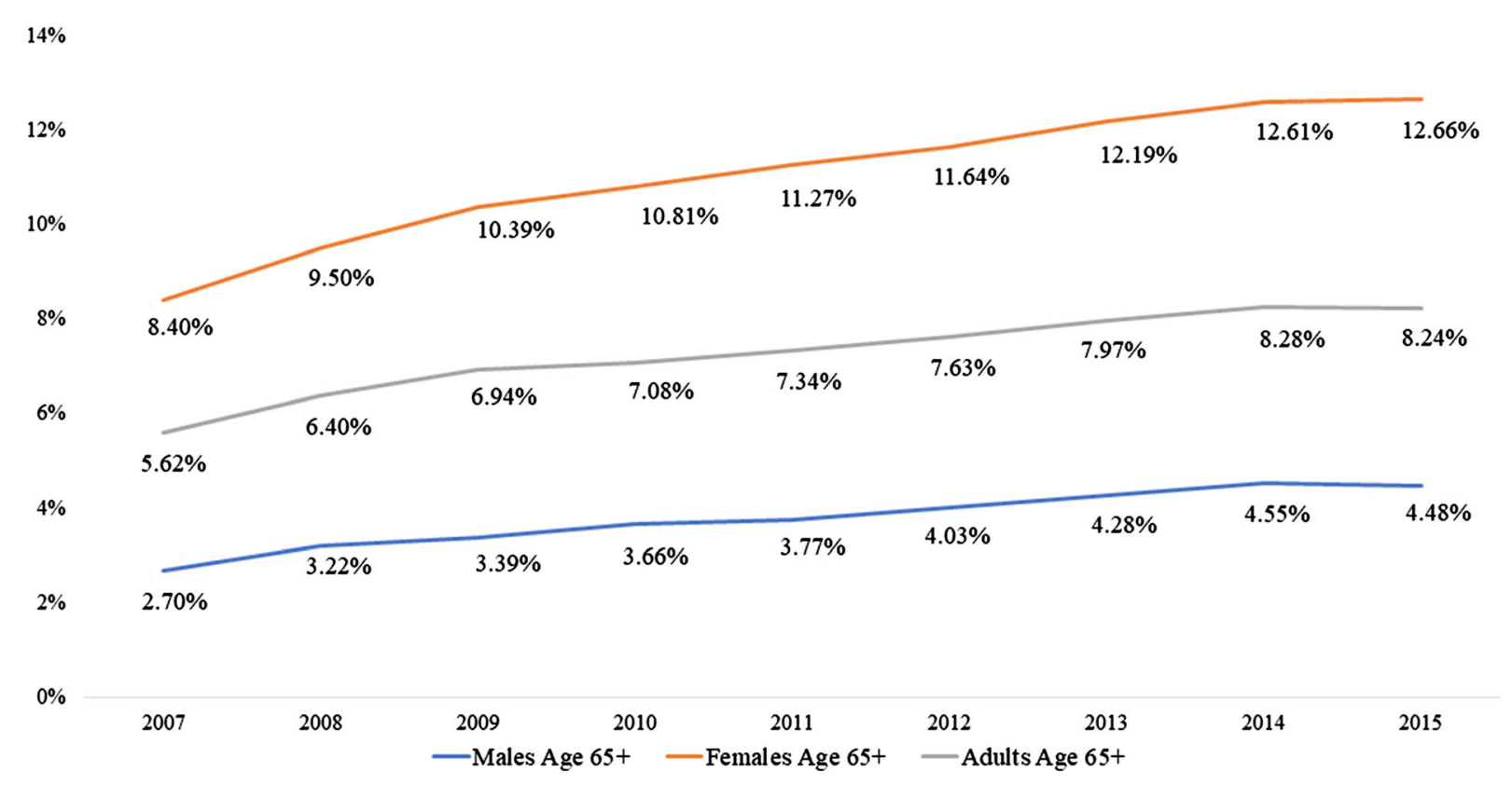

Fig. 1 Prevalence of hypothyroidism among older adults, by sex, 2007-2015

$P=0.010)$ and coronary artery disease $(17.8 \%$ vs. $15.1 \% ; P=0.043)$. There was no statistically significant difference between the two cohorts' TSH levels, with treated patients having a median (IQ) TSH of 2.30 (1.45-4.34) and untreated patients' median (IQ) TSH equal to 2.19 (1.37-4.31) $(P=0.582)$.

Among patients treated with levothyroxine, approximately one-third of treated patients (32.9\%) did not have a TSH laboratory result in their record over the 1-year study period. Less than half (46.0\%) of treated patients were found to have their TSH level in the targeted range of $0.45-4.12 \mathrm{mIU} / \mathrm{l}$, while $17.4 \%$ had a TSH level $>4.12 \mathrm{mIU} / \mathrm{l}$ and $3.7 \%$ had a TSH level $<0.45 \mathrm{mIU} / 1$ (see Fig. 3). Using the updated recommended range of TSH values[30] resulted in modest changes to these results, while requiring that an individual have two or more TSH test results in the post-period resulted in over half of the patients $(52.7 \%)$ failing to meet that threshold (Fig. 3).

Table 2 examines baseline comorbidities and patient characteristics for patients treated with levothyroxine based upon their TSH categorization in the post-period. In general, there were few differences across treatment outcome categories based upon patient comorbidities, although there were statistically significant differences found in patients with either comorbid heart failure $(P<0.001)$ or rheumatoid arthritis $(P=0.022)$. Specifically, patients with either of these comorbidities were most frequently identified as not having their TSH level monitored and least frequently identified as being on-target. Consistent with these results, there were also significant differences in the CCI score $(P<0.001)$ across TSH categories, with patients not monitored having the highest CCI score.

\section{DISCUSSION}

The results of this study show that, among an older, insured population in the US, prevalence rates of hypothyroidism have been increasing over recent years, are larger in women than men and, for both sexes, appear to be higher than have been reported previously $[1,32,33]$. This may be, in part, due to the age of the sample as well as identification of cases by administrative claims rather than TSH tests, which was the method employed in earlier studies. The use of ICD-9 diagnosis codes to identify cases, as was done in this study, allows for a broad characterization of hypothyroidism and its treatment 


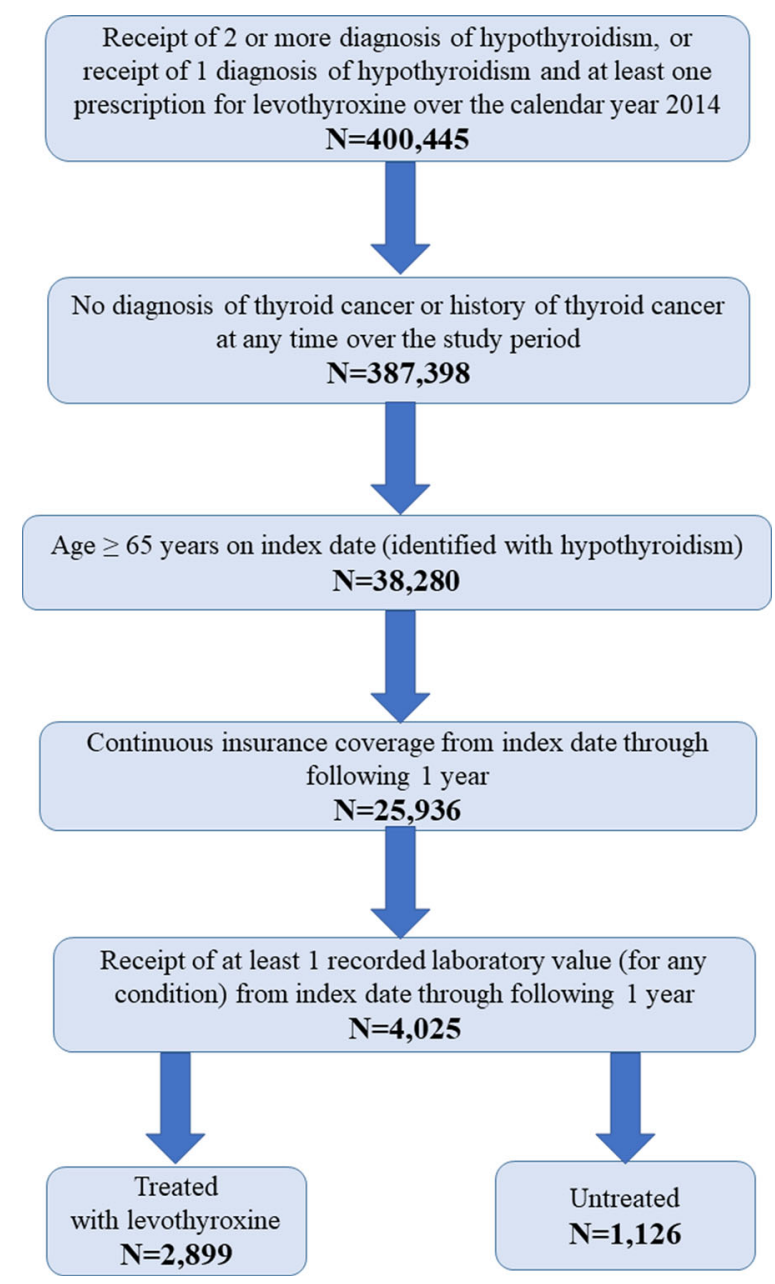

Fig. 2 Inclusion-exclusion criteria and sample size

in the US during recent years. However, the lack of confirmatory laboratory test values for TSH and $\mathrm{T} 4$ does not allow for precision in diagnosing. Increasing rates of diagnosis of hypothyroidism might suggest growth in screening, although it is not clear this reflects more overt hypothyroidism or SCH.

Among these older adults with hypothyroidism, females were less likely than males to be treated with levothyroxine, a finding that is consistent with previous literature indicating that women are treated less aggressively for a number of conditions, including myocardial infarction, heart failure, atrial fibrillation, rheumatoid arthritis and kidney disease [34]. The findings that the older patients who were treated with levothyroxine were in poorer general health (as shown by a higher CCI score and being more likely to have been diagnosed with comorbidities such as type 2 diabetes, hypertension, heart failure or coronary artery disease) suggest that increased contact with medical professionals for the management of comorbidities may have led to an increased likelihood of treatment for hypothyroidism. Given that treatment with levothyroxine may be associated with cardiovascular benefits $[14,24,35]$, it is possible that patients with cardiovascular comorbidities were particularly likely to be prescribed the drug.

The lack of a difference in median TSH levels among patients who were treated with levothyroxine and those who were untreated may, in part, reflect previously reported differences in normal TSH set points based, for example, upon race or gender [12-14]. Alternatively, those who were not treated may have had $\mathrm{SCH}$ with borderline TSH, although this hypothesis could not be tested, as there is no diagnosis code for $\mathrm{SCH}$. Yet another possibility is that at least some individuals in the untreated cohort were diagnosed based on symptoms or while acutely ill in the hospital rather than by laboratory results, which would have shown that their TSH levels were borderline, a possibility that may have been missed since only one laboratory test was required. The findings related to region and prescribing physician will be of interest to prescribers, policymakers and payers who are exploring ways to increase the quality of care while decreasing costs. In this regard, the Northeast region, POS insurance coverage and treatment by endocrinologists are all shown to be targets for improvement in care of older adults with hypothyroidism.

A key finding in this study was that a significant percentage of older adults with hypothyroidism may not have been treated in accordance with recent AACE/ATA guidelines [14]. While recognizing that the dosage of levothyroxine may be different in older adults because they have higher normal serum TSH ranges and more concomitant drug use, the guidelines nevertheless counsel that older patients should receive drug therapy that brings their TSH to within age-based targets or, if an age-based limit for the relevant TSH assay is not 
Table 1 Baseline characteristics and patient comorbidities-all and by treatment status

\begin{tabular}{|c|c|c|c|c|}
\hline & $\begin{array}{l}\text { All patients } \\
(4025) \\
\text { Mean } \pm S D \\
n(\%)\end{array}$ & $\begin{array}{l}\text { Treated with levothyroxine } \\
(N=2899) \\
\text { Mean } \pm \text { SD } \\
n(\%)\end{array}$ & $\begin{array}{l}\text { Untreated } \\
(N=1126) \\
\text { Mean } \pm S D \\
n(\%)\end{array}$ & $P$ value \\
\hline Age (mean; SD) & $69.4 \pm 5.4$ & $69.5 \pm 5.6$ & $69.0 \pm 4.9$ & 0.003 \\
\hline Male sex & $1268(31.5)$ & $946(32.6)$ & $322(28.6)$ & 0.013 \\
\hline Region & & & & 0.002 \\
\hline Northeast & $423(10.5)$ & $287(9.9)$ & $136(12.1)$ & \\
\hline Midwest & $749(18.6)$ & $562(19.4)$ & $187(16.6)$ & \\
\hline South & $2075(51.6)$ & $1490(51.4)$ & $585(52.0)$ & \\
\hline West & $774(19.2)$ & $560(19.3)$ & $214(19.0)$ & \\
\hline Insurance plan type & & & & $<0.001$ \\
\hline EPO & $462(11.5)$ & $332(11.5)$ & $130(11.6)$ & \\
\hline Indemnity & $468(11.6)$ & $384(13.3)$ & $84(7.5)$ & \\
\hline Point of service & $2744(68.2)$ & $1907(65.8)$ & $837(74.3)$ & \\
\hline Other & $351(8.7)$ & $276(9.5)$ & $75(6.7)$ & \\
\hline $\begin{array}{l}\text { Diagnosis physician- } \\
\text { endocrinologist }\end{array}$ & $210(5.2)$ & $118(4.1)$ & $92(8.2)$ & $<0.001$ \\
\hline \multicolumn{5}{|c|}{ General health and comorbidities } \\
\hline CCI (mean; SD) & $1.5 \pm 2.0$ & $1.6 \pm 2.1$ & $1.3 \pm 1.8$ & $<0.001$ \\
\hline Type 1 diabetes & $152(3.8)$ & $110(3.9)$ & $42(3.7)$ & 0.923 \\
\hline Type 2 diabetes & $1153(28.7)$ & $859(29.6)$ & $294(26.1)$ & 0.027 \\
\hline Hypertension & $2789(69.3)$ & $2044(70.5)$ & $745(66.2)$ & 0.007 \\
\hline Dyslipidemia & $3041(75.6)$ & $2203(76.0)$ & $838(74.4)$ & 0.298 \\
\hline Heart failure & $245(6.1)$ & $194(6.7)$ & $51(4.5)$ & 0.010 \\
\hline Coronary artery disease & $685(17.0)$ & $515(17.8)$ & $170(15.1)$ & 0.043 \\
\hline Rheumatoid arthritis & $160(4.0)$ & $119(4.1)$ & $41(3.6)$ & 0.499 \\
\hline Obesity & $683(17.0)$ & $500(17.3)$ & $183(16.3)$ & 0.450 \\
\hline Migraine & $140(3.5)$ & $95(3.3)$ & $45(4.0)$ & 0.263 \\
\hline Depression & $513(12.8)$ & $381(13.1)$ & $132(11.7)$ & 0.225 \\
\hline Bipolar disorder & $64(1.6)$ & $48(1.7)$ & $16(1.4)$ & 0.593 \\
\hline $\mathrm{TSH}^{\mathrm{a}}$ (median, IQ-range) & $2.28(1.42-4.32)$ & $2.30(1.45-4.34)$ & $2.19(1.37-4.31)$ & 0.582 \\
\hline
\end{tabular}

$T$ tests and chi-square tests were used to examine differences in means, medians and proportions, respectively $C C I$ Charlson Comorbidity Index score, EPO exclusive provider organization, HMO health maintenance organization, PPO preferred provider organization, $S D$ standard deviation

${ }^{a}$ TSH laboratory tests conducted during 1 year following the index date 


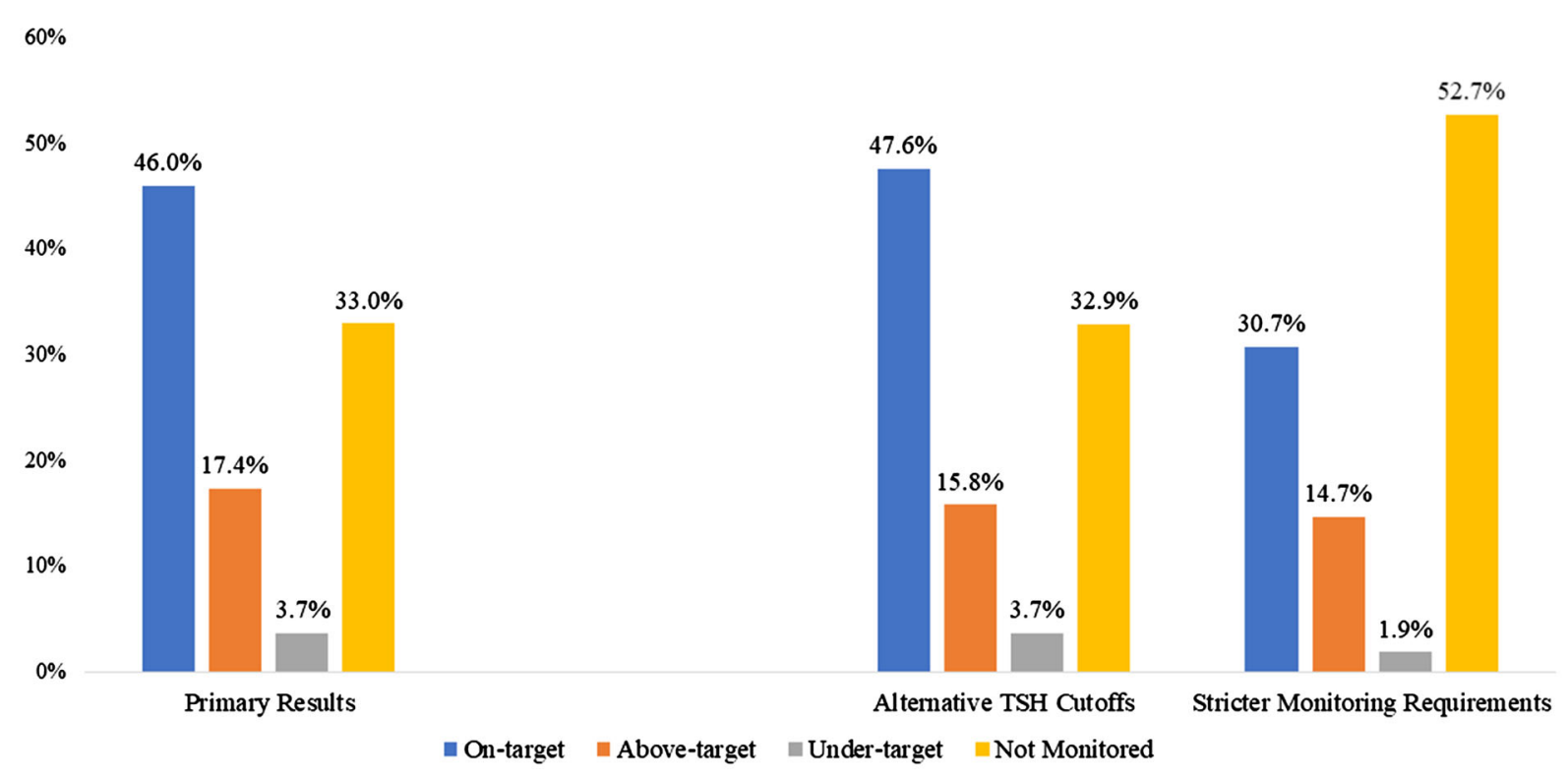

On-target, Above-target and Under-target defined for actual TSH levels relative to recommended target guidelines for older adults (TSH Range $0.45-4.12 \mathrm{mIU} / \mathrm{L}$ ) Alternative TSH cutoffs of appropriate TSH level (TSH Range $0.45-4.50 \mathrm{mIU} / \mathrm{L}$ ) Stricter monitoring requirements identified patients as monitored if they had results of 2 or more TSH tests (instead of only 1) in administrative records during the 1-year post-period.

Fig. 3 TSH categories for older patients treated with levothyroxine, main and sensitivity analyses

available, within the range of TSH target values used in this study [14]. In contrast to this recommendation, more than one-quarter of the older patients in this investigation did not fill a prescription for levothyroxine therapy. The rate of untreated hypothyroidism in the general population of older Americans is likely even higher since the results in this study were based upon an insured population that may be expected to have better access to care than uninsured older individuals. Also, many people may not be screened for the disease, despite the guidelines that state that screening should be considered in individuals $\geq 60$ years, particularly those with risk factors for hypothyroidism [14]. Hence, results of this study may be an underestimate of the problem. Previous research has found that the cost-effectiveness of screening is most favorable in older women [36]. However, a more recent study was unable to draw any conclusions about the overall efficacy of treating patients found by screening to have subclinical thyroid function [37].

While a previous study of hypothyroid patients aged $\geq 65$ years found $41 \%$ and $16 \%$ rates of over- and under-treatment, respectively
[38], the present findings revealed that $3.7 \%$ of the older patients with hypothyroidism and treated with levothyroxine had TSH levels below target and $17.4 \%$ had TSH levels above target. Clinical guidelines recommend initiating older patients on a low dose of levothyroxine and then titrating slowly to the treatment target, based on TSH monitoring [14, 30]. Recent research supports that older patients may need "several dose adjustments...to achieve target serum TSH levels" [39]. However, the results of the present study suggest that only a minority of older patients receive sufficient dose titration to achieve TSH targets. These findings were based upon a TSH recommended range published by AACE/ATA in 2012, which may be most relevant to the 2014-2015 study period. Using the updated guidelines, published in 2014 , in the sensitivity analysis did not alter the main conclusions.

Of course, ascertainment of the TSH target being achieved presupposes that monitoring takes place and laboratory tests are conducted. However, almost one-third of the sample did not have a single TSH laboratory value from the post-period recorded in the clinical data, which 
Table 2 Baseline characteristics and patient comorbidities for levothyroxine-treated patients by TSH category

\begin{tabular}{|c|c|c|c|c|c|}
\hline \multirow[t]{2}{*}{ Characteristics } & \multicolumn{4}{|l|}{ Total $N=2899$} & \multirow[t]{2}{*}{$P$ value } \\
\hline & $\begin{array}{l}\text { Above target } \\
(N=504) \\
\text { Mean } \pm \text { SD } \\
n(\%)\end{array}$ & $\begin{array}{l}\text { On target } \\
(N=1334) \\
\text { Mean } \pm S D \\
n(\%)\end{array}$ & $\begin{array}{l}\text { Under target } \\
(N=106) \\
\text { Mean } \pm \text { SD } \\
n(\%)\end{array}$ & $\begin{array}{l}\text { Not monitored } \\
(N=955) \\
\text { Mean } \pm \text { SD } \\
n(\%)\end{array}$ & \\
\hline Age (mean; SD) & $69.2 \pm 5.4$ & $69.2 \pm 5.4$ & $69.0 \pm 4.8$ & $70.1 \pm 6.1$ & $<0.001$ \\
\hline Male sex & $184(36.5)$ & $430(32.2)$ & $31(29.3)$ & $301(31.5)$ & 0.201 \\
\hline Region & & & & & $<0.001$ \\
\hline Northeast & $56(11.1)$ & $125(9.4)$ & $14(13.2)$ & $92(9.6)$ & \\
\hline Midwest & $68(13.5)$ & $235(17.6)$ & $19(17.9)$ & $240(25.1)$ & \\
\hline South & $298(59.1)$ & $697(52.3)$ & $46(43.4)$ & $449(47.0)$ & \\
\hline West & $82(16.3)$ & $277(20.8)$ & $27(25.5)$ & $174(18.2)$ & \\
\hline Insurance plan type & & & & & $<0.001$ \\
\hline EPO & $67(13.3)$ & $168(12.6)$ & $8(7.6)$ & $89(9.3)$ & \\
\hline Indemnity & $37(7.3)$ & $141(10.6)$ & $15(14.2)$ & $191(20.0)$ & \\
\hline Point of service & $347(68.9)$ & $885(66.3)$ & $74(69.8)$ & $601(62.9)$ & \\
\hline Other & $53(10.5)$ & $140(10.5)$ & $9(8.5)$ & $74(7.8)$ & \\
\hline $\begin{array}{l}\text { Diagnosis physician- } \\
\text { endocrinologist }\end{array}$ & $21(4.2)$ & $55(4.1)$ & $2(1.9)$ & $40(4.2)$ & 0.717 \\
\hline \multicolumn{6}{|c|}{ General health and comorbidities } \\
\hline CCI (mean; SD) & $1.6 \pm 2.2$ & $1.4 \pm 1.9$ & $1.4 \pm 1.6$ & $2.0 \pm 2.3$ & $<0.001$ \\
\hline Type 1 diabetes & $19(3.8)$ & $46(3.5)$ & $6(5.7)$ & $39(4.1)$ & 0.644 \\
\hline Type 2 diabetes & $155(30.8)$ & $381(28.6)$ & $25(23.6)$ & $298(31.2)$ & 0.258 \\
\hline Hypertension & $360(71.4)$ & $923(69.2)$ & $76(71.7)$ & $685(71.7)$ & 0.557 \\
\hline Dyslipidemia & $395(78.4)$ & $1026(76.9)$ & $77(72.6)$ & $705(73.8)$ & 0.151 \\
\hline Heart failure & $27(5.4)$ & $69(5.2)$ & $7(6.6)$ & $91(9.5)$ & $<0.001$ \\
\hline Coronary artery disease & $95(18.9)$ & $225(16.9)$ & $18(17.0)$ & $177(18.5)$ & 0.665 \\
\hline Rheumatoid arthritis & $19(3.8)$ & $41(3.1)$ & $5(4.7)$ & $54(5.7)$ & 0.022 \\
\hline Obesity & $89(17.7)$ & $239(17.9)$ & $19(17.9)$ & $153(16.0)$ & 0.678 \\
\hline Migraine & $14(2.8)$ & $44(3.3)$ & $3(2.8)$ & $34(3.6)$ & 0.872 \\
\hline Depression & $67(13.3)$ & $172(12.9)$ & $13(12.3)$ & $129(13.5)$ & 0.966 \\
\hline Bipolar disorder & $10(2.0)$ & $17(1.3)$ & $2(1.9)$ & $19(2.0)$ & 0.529 \\
\hline $\mathrm{TSH}^{\mathrm{a}}$ (median, IQ-range) & $7.58(5.51-10.97)$ & $1.87(1.37-2.70)$ & $0.15(0.07-0.27)$ & & \\
\hline
\end{tabular}

Ranges based upon guidelines that recommend TSH between 0.45 and $4.12 \mathrm{mIU} / \mathrm{l}$

Analysis of variance and chi-square tests were used to examinee differences in means, medians and proportions, respectively $C C I$ Charlson Comorbidity Index score, EPO exclusive provider organization, HMO health maintenance organization, $P P O$ preferred provider organization, $S D$ standard deviation

${ }_{\text {a }}$ TSH laboratory tests conducted during 1-year following the index date 
suggests that monitoring is an area for improvement for this population. Furthermore, less than half $(47.3 \%)$ of the patients treated with levothyroxine received two or more TSH tests in the post-period, providing further evidence that patients who were under-treated may not have had their doses titrated or their TSH levels monitored appropriately.

Over-treatment of hypothyroidism has been associated with serious complications, including cardiac arrhythmias, bone loss and death [40], and it is particularly problematic for older individuals [30]. For instance, a study among patients aged $\geq 60$ years found that those with low serum thyrotropin concentrations had a three-times higher risk of atrial fibrillation over the following 10-year period [41]. At the same time, undertreated hypothyroidism represents inappropriately controlled hypothyroidism, which has been associated with substantial morbidity, including atherogenic lipid profiles [30, 32] and cardiovascular disease [16]. In this study, examination of rates of comorbidities across TSH outcome categories revealed significant differences for only two of the comorbidities-heart failure and rheumatoid arthritis. Perhaps the 1-year follow-up period was not long enough for some of the conditions to manifest themselves in this study. However, it is noted that among treated patients, those who did not have their TSH levels monitored had the highest CCI score and were more frequently diagnosed with comorbid heart failure and rheumatoid arthritis. One possible explanation for this result is that physicians and patients were more focused on these comorbid conditions and, as a result, less likely to monitor TSH. Another possibility is that these acutely ill patients were not stable enough for monitoring that would allow separation of the 'euthyroid sick' from those with real hypothyroidism. (We thank an anonymous referee for this observation.)

The results of this study should be considered in the context of the following limitations. First, the study presents descriptive results only, and there were no hypotheses tested using adjusted models. The results are associations only; no causal inferences were possible with this study design. Second, the patients in this well-insured population may not be representative of all older individuals in the US with hypothyroidism. Third, as with all studies utilizing administrative claims data, the results are dependent upon accuracy of the diagnosis codes and, in this particular case, the relatively small number of individuals with TSH test results limited their usefulness in confirming the coding. A related problem was the lack of an ICD-9 code for SCH. Fourth, some individuals may have had TSH laboratory tests conducted but the values were not captured in the database. Finally, levothyroxine use was assessed by the patient having filled a prescription for that medication. Whether the patient actually took the drug and was adherent to the prescribing regimen, which may have affected TSH findings, was not examined. Despite these limitations, the results reported were robust to a range of sensitivity analyses.

\section{CONCLUSIONS}

Findings from this study indicate that many older adults with hypothyroidism may not have been receiving medical care that complied with recent clinical practice guidelines. Many were not receiving levothyroxine therapy, and a substantial proportion of those who were receiving such therapy were not being monitored to determine whether their dosage was appropriate. Moreover, the laboratory results of those who were treated in this sample suggest that a significant proportion were under-treated, while a small proportion was over-treated. In conclusion, this study reveals a number of areas to target that may lead to improvement in the treatment of older adults with hypothyroidism.

\section{ACKNOWLEDGEMENTS}

The authors would like to thank Patricia Platt and Michael Treglia for their assistance in the manuscript preparation.

Funding. AbbVie provided financial support for this study, the Rapid Service Fee and Open Access Fee. 
Authorship. All named authors meet the International Committee of Medical Journal Editors (ICMJE) criteria for authorship for this article, take responsibility for the integrity of the work as a whole, and have given their approval for this version to be published. AbbVie participated in the study design, research, data collection, analysis, and interpretation of data, writing, reviewing, and approving the publication.

Authorship Contributions. All authors had full access to all of the data in this study and take complete responsibility for the integrity of the data and accuracy of the data analysis.

Disclosures. Drs. Ramon Espaillat and Jamie Vora are employees of AbbVie and may own AbbVie stocks or options. Zsolt Hepp was an AbbVie employee when this study was undertaken. Zsolt Hepp is currently affiliated at Global Health Economics and Outcomes Research, Seattle Genetics. Maureen J. Lage is the Managing Member of HealthMetrics Outcomes Research, which was compensated for work on this project not related to authorship.

Compliance with Ethics Guidelines. The data used in this study are fully de-identified and HIPAA compliant. Given the retrospective nature of the study design and the de-identified data, the study was exempt from internal review board evaluation.

Data Availability. Please contact the corresponding author for access to data, subject to licensing restrictions between AbbVie, Inc., and Optum.

Open Access. This article is licensed under a Creative Commons Attribution-NonCommercial 4.0 International License, which permits any non-commercial use, sharing, adaptation, distribution and reproduction in any medium or format, as long as you give appropriate credit to the original author(s) and the source, provide a link to the Creative Commons licence, and indicate if changes were made. The images or other third party material in this article are included in the article's
Creative Commons licence, unless indicated otherwise in a credit line to the material. If material is not included in the article's Creative Commons licence and your intended use is not permitted by statutory regulation or exceeds the permitted use, you will need to obtain permission directly from the copyright holder. To view a copy of this licence, visit http:// creativecommons.org/licenses/by-nc/4.0/.

\section{REFERENCES}

1. Hollowell JG, Staehling NW, Flanders WD, et al. Serum TSH, $\mathrm{T}_{4}$, and thyroid antibodies in the United States population (1988-1994): National Health and Nutrition Examination Survey (NHANES III). J Clin Endocrinol Metab. 2002;87(2):489-99. https://doi.org/10.1210/jcem.87.2.8182.

2. American Thyroid Association. General Information/Press Room. American Thyroid Association. https://www.thyroid.org/media-main/press-room/. Accessed Dec 18, 2019.

3. Vanderpump MPJ. The epidemiology of thyroid disease. Br Med Bull. 2011;99:39-51. https://doi. org/10.1093/bmb/ldr030.

4. Golden SH, Robinson KA, Saldanha I, Anton B, Ladenson PW. Prevalence and incidence of endocrine and metabolic disorders in the United States: a comprehensive review. J Clin Endocrinol Metab. 2009;94(6):1853-78. https://doi.org/10.1210/jc. 2008-2291.

5. Berber E. Causes of hypothyroidism. EndocrineWeb. https://www.endocrineweb.com/conditions/ hypothyroidism/causes-hypothyroidism. Accessed June 07, 2017.

6. Autoimmune Registry. Estimates of prevalence for autoimmune disease. The Autoimmune Registry. http://www.autoimmuneregistry.org/autoimmunestatistics/. Accessed Oct 04, 2017.

7. Gesing A, Lewiński A, Karbownik-Lewińska M. The thyroid gland and the process of aging; what is new? Thyroid Res. 2012;5:16. https://doi.org/10. 1186/1756-6614-5-16.

8. Cooper DS, Biondi B. Subclinical thyroid disease. Lancet. 2012;379(9821):1142-54. https://doi.org/ 10.1016/S0140-6736(11)60276-6.

9. Cappola AR, Fried LP, Arnold AM, et al. Thyroid status, cardiovascular risk, and mortality in older 
adults. JAMA. 2006;295(9):1033-41. https://doi. org/10.1001/jama.295.9.1033.

10. Biondi B, Cooper DS. The clinical significance of subclinical thyroid dysfunction. Endocr Rev. 2008;29(1):76-131. https://doi.org/10.1210/er. 2006-0043.

11. Bensenor IM, Olmos RD, Lotufo PA. Hypothyroidism in the elderly: diagnosis and management. Clin Interv Aging. 2012;7:97-111. https://doi.org/ 10.2147/CIA.S23966.

12. Boucai L, Hollowell JG, Surks MI. An approach for development of age-, gender-, and ethnicity-specific thyrotropin reference limits. Thyroid. 2011;21(1): 5-11. https://doi.org/10.1089/thy.2010.0092.

13. Bremner AP. Age-related changes in thyroid function: a longitudinal study of a community-based cohort. J Clin Endocrinol Metab. 2012;97(5): $1554-62$.

14. Garber JR, Cobin RH, Gharib H, et al. Clinical practice guidelines for hypothyroidism in adults: cosponsored by the American Association of Clinical Endocrinologists and the American Thyroid Association. Endocr Pract. 2012;18(6):988-1028. https://doi.org/10.4158/EP12280.GL.

15. Bemben DA, Winn P, Hamm RM, Morgan L, Davis A, Barton E. Thyroid disease in the elderly. Part 1. Prevalence of undiagnosed hypothyroidism. J Fam Pract. 1994;38(6):577-82.

16. Rodondi N, den Elzen WPJ, Bauer DC, et al. Subclinical hypothyroidism and the risk of coronary heart disease and mortality. JAMA. 2010;304(12): 1365-74. https://doi.org/10.1001/jama.2010.1361.

17. Ning Y, Cheng YJ, Liu LJ, et al. What is the association of hypothyroidism with risks of cardiovascular events and mortality? A meta-analysis of 55 cohort studies involving 1,898,314 participants. BMC Med. 2017;15(1):21. https://doi.org/10.1186/ s12916-017-0777-9.

18. Lee JS, Buzková P, Fink HA, et al. Subclinical thyroid dysfunction and incident hip fracture in older adults. Arch Intern Med. 2010;170(21):1876-83. https://doi.org/10.1001/archinternmed.2010.424.

19. Grossman A, Weiss A, Koren-Morag N, Shimon I, Beloosesky Y, Meyerovitch J. Subclinical thyroid disease and mortality in the elderly: a retrospective cohort study. Am J Med. 2016;129(4):423-30. https://doi.org/10.1016/j.amjmed.2015.11.027.

20. Feller M, Snel M, Moutzouri E, et al. Association of thyroid hormone therapy with quality of life and thyroid-related symptoms in patients with subclinical hypothyroidism: a systematic review and meta-analysis. JAMA. 2018;320(13):1349-59. https://doi.org/10.1001/jama.2018.13770.

21. Stott DJ, Rodondi N, Kearney PM, et al. Thyroid hormone therapy for older adults with subclinical hypothyroidism. N Engl J Med. 2017;376(26): 2534-44. https://doi.org/10.1056/NEJMoa1603825.

22. Hennessey JV, Espaillat R. Subclinical hypothyroidism: a historical view and shifting prevalence. Int J Clin Pract. 2015;69(7):771-82. https://doi.org/ 10.1111/ijcp.12619.

23. Surks MI, Goswami G, Daniels GH. The thyrotropin reference range should remain unchanged. J Clin Endocrinol Metab. 2005;90(9):5489-96. https://doi. org/10.1210/jc.2005-0170.

24. Javed Z, Sathyapalan T. Levothyroxine treatment of mild subclinical hypothyroidism: a review of potential risks and benefits. Ther Adv Endocrinol Metab. 2016;7(1):12-23. https://doi.org/10.1177/ 2042018815616543.

25. Deyo RA, Cherkin DC, Ciol MA. Adapting a clinical comorbidity index for use with ICD-9-CM administrative databases. J Clin Epidemiol. 1992;45(6): 613-9.

26. Quan H, Sundararajan V, Halfon $P$, et al. Coding algorithms for defining comorbidities in ICD-9-CM and ICD-10 administrative data. Med Care. 2005;43(11):1130-9.

27. Furukawa S, Yamamoto S, Todo Y, et al. Association between subclinical hypothyroidism and diabetic nephropathy in patients with type 2 diabetes mellitus. Endocr J. 2014;61(10):1011-8.

28. Radhakrishnan R, Calvin S, Singh JK, Thomas B, Srinivasan K. Thyroid dysfunction in major psychiatric disorders in a hospital based sample. Indian J Med Res. 2013;138(6):888-93.

29. Lisotto C, Mainardi F, Maggioni F, Zanchin G. The comorbidity between migraine and hypothyroidism. J Headache Pain. 2013;14(Suppl 1):P138. https://doi.org/10.1186/1129-2377-14-S1-P138.

30. Jonklaas J, Bianco AC, Bauer AJ, et al. Guidelines for the treatment of hypothyroidism: prepared by the American Thyroid Association Task Force on Thyroid Hormone Replacement. Thyroid. 2014;24(12): 1670-751. https://doi.org/10.1089/thy.2014.0028.

31. Cooper GS, Stroehla BC. The epidemiology of autoimmune diseases. Autoimmun Rev. 2003;2(3): 119-25.

32. Canaris GJ, Manowitz NR, Mayor G, Ridgway EC. The Colorado thyroid disease prevalence study. Arch Intern Med. 2000;160(4):526-34. 
33. Sawin CT, Castelli WP, Hershman JM, McNamara P, Bacharach P. The aging thyroid. Thyroid deficiency in the Framingham Study. Arch Intern Med. 1985;145(8):1386-8.

34. Regitz-Zagrosek V. Sex and gender differences in health. EMBO Rep. 2012;13(7):596-603. https:// doi.org/10.1038/embor.2012.87.

35. Serter R, Demirbas B, Korukluoglu B, Culha C, Cakal E, Aral Y. The effect of L-thyroxine replacement therapy on lipid based cardiovascular risk in subclinical hypothyroidism. J Endocrinol Investig. 2004;27(10):897-903. https://doi.org/10.1007/ BF03347530.

36. Danese MD, Powe NR, Sawin CT, Ladenson PW. Screening for mild thyroid failure at the periodic health examination: a decision and cost-effectiveness analysis. JAMA. 1996;276(4):285-92. https:// doi.org/10.1001/jama.1996.03540040029029.

37. Rugge JB, Bougatsos C, Chou R. Screening and treatment of thyroid dysfunction: an evidence review for the US Preventive Services Task Force.
Ann Intern Med. 2015;162(1):35. https://doi.org/ 10.7326/m14-1456.

38. Somwaru LL, Arnold AM, Joshi N, Fried LP, Cappola AR. High frequency of and factors associated with thyroid hormone over-replacement and under-replacement in men and women aged 65 and over. J Clin Endocrinol Metab. 2009;94(4):1342-5. https://doi.org/10.1210/jc.2008-1696.

39. Razvi S, Ingoe L, Ryan V, Pearce SHS, Wilkes S. Study of Optimal Replacement of Thyroxine in the Elderly (SORTED) -results from the feasibility randomised controlled trial. Thyroid Res. 2016;9:5. https://doi.org/10.1186/s13044-016-0034-x.

40. Synthroid Prescribing Information. http://www. rxabbvie.com/pdf/synthroid.pdf. Accessed Oct 05, 2017.

41. Sawin CT, Geller A, Wolf PA, et al. Low serum thyrotropin concentrations as a risk factor for atrial fibrillation in older persons. $\mathrm{N}$ Engl J Med. 1994;331(19):1249-52. https://doi.org/10.1056/ NEJM199411103311901. 